\title{
Canguilhem e as ciências da vida
}

CANGUILHEM, G.

Estudos de História e de Filosofia das Ciências: concernentes aos vivos e à vida

Rio de Janeiro: Forense Universitária, 2012

\section{| ${ }^{1}$ Lizandro Lui |}

1 Instituto de Filosofia e Ciências Humanas, Universidade Federal do Rio Grande do Sul, Campos do Vale. Porto Alegre-RS, Brasil. Endereço eletrônico: lizandrolui@gmail.com

Recebida em: 10/04/2014

Aprovada em: 11/03/2015

DOI: http://dx.doi.org/10.1590/S0103-733120150002000018

O objetivo da resenha é apresentar os principais pontos da obra de Georges Canguilhem - Estudos de História e de Filosofia das Ciências: concernentes aos vivos e à vida - recentemente lançada no Brasil. Não será apresentado um resumo sistemático de cada capítulo da obra, mas serão pontuadas questões perpassam os capítulos. É importante ressaltar que o livro não foi escrito de modo uniforme; é um compilado de palestras, aulas e conferências ministradas por Canguilhem ao longo de sua careira como pesquisador e docente em torno do mesmo assunto: o desenvolvimento das ciências que investigam a vida. Isso não reduz em nada a qualidade e a pertinência da obra, visto que todos os capítulos foram organizados no sentido em que é possível compreender a evolução das discussões a respeito da filosofia e epistemologia da ciência empreendida pelo autor.

O livro é dividido em três grandes partes: a primeira, chamada de "Comemoraçôes", enfoca as primeiras contribuiçōes no campo filosófico da ciência, remete a Galileu e Copérnico. Na segunda parte, "Interpretações", Canguilhem discute a forma como a ciência foi entendida no século XVIII, tendo como base o pensamento de Comte, Darwin, Claude Bernard e Gaston Bachelard. Na última parte do livro, intitulada "Investigações", Canguilhem não enfoca o pensamento de um pensador ou cientista em específico, como fizera nos capítulos precedentes, mas o desenvolvimento dos campos da Biologia, 
Fisiologia e Medicina, apontando os avanços, limites e possibilidades que esses campos apresentaram desde sua concepção como campo de investigaçôes e conhecimento até a contemporaneidade. É importante lembrar que o objetivo da obra é apresentar a história dos sistemas de pensamento que compõem o campo das ciências da vida.

A primeira parte do livro enfoca a atmosfera científica do mundo de Copérnico. O primeiro grande passo dado da época, aponta Canguilhem, foi considerar o processo de formulação de conhecimento um trabalho Canguilhem aponta, na primeira parte da obra, as primeiras observaçóes e experiências feitas no campo da anatomia. Outro ponto importante, desta vez creditado a Galileu, é o início dos usos científicos de instrumentos e ferramentas. O primeiro instrumento apontado pelo autor é o telescópio. Canguilhem ressalta como importante, no entanto, não a invenção do telescópio em si, mas sim o uso sistemático desse objeto para fins de investigação científica.

Referindo-se à segunda parte do livro, Canguilhem discute os aspectos centrais da obra de Charles Darwin e apresenta os postulados desenvolvidos por Augusto Comte. Trazendo os conceitos de seleção natural e evolução, Canguilhem (2012, p. 117) ressalta o aspecto de genealogia que a obra de Darwin carrega, mais especificamente, que o cientista inglês não apenas trouxe paralelismos em relação do homem com outras espécies, mas apresentou o homem como resultado efetivo de uma descendência, e não como um ideal que foi alcançado.

Em relação ao que Canguilhem escreve referente à biologia e a redução da vida ao biológico, Czeresnia (2010, p. 714) afirma:

Pensar a vida fora de uma explicação possível no âmbito das ciências da natureza é uma questão controversa. Canguilhem tem claro que a biologia opera uma redução ao se ancorar na físico-química para explicar a vida. Esta redução, em que a biologia se torna satélite das chamadas ciências naturais, segundo ele, desvaloriza o objeto biológico em sua especificidade.

Canguilhem também vai tratar das contribuições de Claude Bernard ao campo epistemológico das ciências médicas. A primeira grande contribuição de Bernard apontada pelo autor é o uso da experimentação como parte constitutiva do processo de desenvolvimento da ciência, em especial da medicina. Segundo sua observação, até então tida como passiva e contemplativa, a medicina experimental é apresentada como uma ciência conquistadora (Canguilhem p. 135). Essa 
modificação no entendimento do processo de produção de conhecimento é apontada por Canguilhem como fundamental no processo de compreensão do desenvolvimento das ciências da saúde. A experimentação proposta por Bernard abriria um novo horizonte no fazer ciência médica. Canguilhem situa o livro de Claude Bernard - Introduction à l'étude de la médicine expérimentale (1865) - como importante marco na formação do campo da medicina do século XIX na França.

Canguilhem usa o argumento de Bernard para ilustrar a mudança no campo epistemológico das ciências médicas do século XIX. Bernard, explica o autor, embora não descartasse os postulados da medicina vigente no momento calcada principalmente na observação e na classificação de doenças, sintomas, tratamentos e diagnósticospostuva a medicina experimental como o segundo passo no campo da medicina (p. 137). Outro grande avanço do sistema de pensamento de Bernard apontado pelo autor é o modelo de fazer ciência em relação aos postulados teóricos vigentes. Canguilhem cita passagens na obra de Bernard onde é dito que o experimentador sacrifica quantas teorias forem necessárias para avançar. $\mathrm{Na}$ obra, é também enfocado o desenvolvimento da fisiologia enquanto ciência. Nesse aspecto, Canguilhem (2012, p. 295) ressalta o surgimento do primeiro tratado de fisiologia publicado no século XIX de Johannes Müller. Mais uma vez, o pensador francês não enfocará o conteúdo da obra, mas a atmosfera científica da qual ela foi concebida e que tipo de estatuto ela conferia ao próprio campo em que inseria. $\mathrm{O}$ autor irá pontuar que, nesse tratado de fisiologia, há um grande sinal de ciência autêntica quando Müller enfatizaa própria ignorância frente a um aspecto específico da fisiologia (no caso, o estudo das glândulas suprarrenais). Conforme Canguilhem (2012, p. 295):

O primeiro grande tratado de fisiologia publicado no século XIX [...] contém somente, concernente à tireoide, cinco linhas, cujas últimas palavras são: "Ignorase qual é a função da tireoide". Essa confissão lacônica renova a conclusão do artigo sobre as suprarrenais: "A função das cápsulas suprarrenais é desconhecida”.

Dessa forma, admitindo que não sabe, o campo das ciências médicas assume uma postura até então impensável, e, ao mesmo tempo, abre-se uma lacuna em que é permitida a construção de conhecimento. É a partir dessa nova mudança de entendimento sobre a própria ação de conhecer o mundo, e mais especificamente, a de conhecer o próprio corpo, que as ciências médicas do século XIX vão desenvolver seu arcabouço de conhecimentos. O autor vai pontuar o 
desenvolvimento de um campo epistemológico em que o homem vai aos poucos se voltando a si mesmo, a sua própria natureza e ao funcionamento do seu corpo. Nesse aspecto da argumentação de Canguilhem, o autor aproxima-se muito da seminal obra de Michel Foucault - As palavras e as coisas (originalmente escrito em 1966) -, onde também é investigado o desenvolvimento das ciências humanas, da economia política, da biologia e da filologia - ciências que investigam o próprio homem, e este se torna pesquisador e pesquisado.

Tratando agora do espírito científico inaugurado no século XIX pela medicina, Canguilhem (2012, p. 370) afirma que "[n]ão é o médico que cura o doente. É a presença da forma da saúde na atividade médica que é precisamente a causa da cura”. Ou seja, essa passagem ilustra a questão da despersonalização do processo curativo. A cura não se deve exclusivamente ao médico, mas aos conhecimentos que este soube operar sobre o paciente para que fosse possível a cura. $\mathrm{O}$ médico, em si, não é o responsável, mas a ciência médica. Neste aspecto, Canguilhem discutirá a ciência enquanto concebida enquanto arte e como ela também foi, paulatinamente, incorporando o estatuto de ciência. $\mathrm{O}$ autor também vai pontuar que grande parte dos conhecimentos de que a medicina passou a fazer uso foi proveniente de outros campos, como da química e sobretudo da biologia.

Analisando a parte final da obra, a discussão de Canguilhem aproxima-se da contemporaneidade. $\mathrm{O}$ autor se debruça sobre dois aspectos da Historia da Ciência: a formulação dos conceitos na área das ciências da vida e como esses conceitos vão orientar o acesso ao factual para ter acesso à vida. Ao mesmo tempo, o autor inverte a lógica e discute como a vida possibilitou o encontro do homem com o que ele chama de "Inteligência". A discussão entre o significante e o significado está presente na academia francesa desde Bachelard (1996) e principalmente Foucault (2000), mas Canguilhem se questiona a respeito disso olhando para as ciências da vida, e como a formulação de abstrações conceituais possibilita ter acesso ao vivo. CZERESNIA (2010, p. 720) afirma:

A categoria vida surge articulada às de trabalho e linguagem. Surgiram em uma mesma base epistêmica no sentido da sua origem de perspectiva dualista. Porém, do ponto de vista da construção epistemológica do homem, houve uma profunda cisão em que o corpo foi concebido como organismo enquanto linguagem e trabalho foram compreendidos de modo imaterial e em estatuto de cientificidade diferenciado. 
Em um capítulo intitulado "Poder e limites da racionalidade em medicina",

Canguilhem ressalta a importância que a medicina exerceu sobre a vida das pessoas desde o século XIX. Cita exemplos como a descoberta dos micróbios, as pesquisas de Pasteur, a descoberta do antibiótico e o desenvolvimento da vacinação que possibilitaram o aumento da expectativa de vida. Porém o autor ainda ressalta que, por mais avançada que a ciência médica se encontre contemporaneamente e por mais racionalizada que possa estar, há ainda aspectos que podem ser postos em questão. Um deles, segundo Canguilhem (p. 446) é o efeito placebo. O autor se questiona se é possível, nesse caso, distinguir a cura objetiva da subjetiva.

Em vias de conclusão, Canguilhem colocará em questão o próprio paciente: segundo o autor, ele não pode ser mais tomado apenas como o local onde a doença se enraíza, mas um sujeito capaz de expressão, com um conhecimento acumulado de si mesmo. Segundo o autor (p. 450), é impossível, do ponto de vista da racionalidade médica, anular a subjetividade da experiência vivida pelo paciente.

Considerando o conjunto da obra de Canguilhem, é possível identificar que o autor está preocupado com as condições de produção e emergência do conhecimento a respeito da vida. Valendo-se de uma tradição francesa de estudos sobre a História das Ciências, desde Alexandre Koyré, Gaston Bachelard e seu contemporâneo Michel Foucault, Canguilhem elabora uma produtiva discussão nesse livro, capaz de questionar a história das ciências médicas e biológicas que tem implicações sobre o modo como é entendida a vida.

\section{Referências}

BACHELARD, G. A formação do espirito científico: contribuição para uma psicanálise do conhecimento. Rio de Janeiro: Contraponto, 1996.

CZERESNIA, D. Canguilhem e o caráter filosófico das ciências da vida. Physis: Revista de Saúde Coletiva. Rio de Janeiro, v. 20, n. 3, p. 709-727, 2010.

FOUCAULT, M. As palavras e as coisas: uma arqueologia das ciências humanas. São Paulo: Martins Fontes, 2000. 